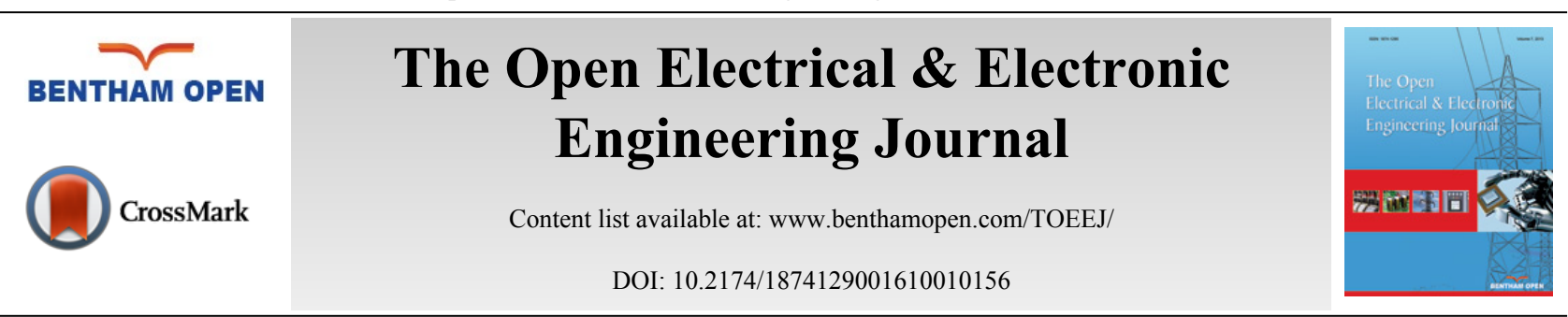

RESEARCH ARTICLE

\title{
Three-terminal Hybrid HVDC Transmissions Control Strategies for Bundled Wind-thermal Power Plants
}

\author{
Wu Jiahui ${ }^{*}$, a , Wang Haiyun ${ }^{\mathrm{a}}$, Wang Weiqing ${ }^{\mathrm{a}}$ and Zhang Qiang ${ }^{\mathrm{b}}$ \\ ${ }^{a}$ College of Electrical Engineering, Xingjiang University, Urumqi, XinJiang, PR China \\ ${ }^{b}$ Electric Power Research Institute, Urumqi, XinJiang, PR China
}

Received: May 21, 2016

Revised: July 13, 2016

Accepted: August 30, 2016

\begin{abstract}
This paper evaluates application feasibility of a Hybrid Multi-terminal HVDC system and wind-thermal-bundled plants simulated in DIgSLIENT PowerFactory environment. The proposed hybrid MTDC system consists of two line-communicated converters (LCC), which are connected to both wind farms and thermal power plants, and one voltage source converter (VSC) at the grid side. Control strategies for each converter are designed to handle this system under different disturbance conditions. Simulation results show that the wind power fluctuation can be compensated by the thermal-generated power. Results demonstrate the effectiveness of the proposed control strategies of the hybrid MTDC system compared to a conventional MTDC system. The proposed scheme combines advantages of both LCC and VSC HVDC systems and provides a new way to transmit wind power over long distances to the main grid.
\end{abstract}

Keywords: Control strategy, Converter station, Hybrid HVDC, LCC-HVDC, VSC-HVDC, Wind-thermal-bundled power system.

\section{INTRODUCTION}

Over the recent years, worldwide demand for energy has been steadily growing. It is expected that by the year 2035 , renewable sources of energy would be generating more than $25 \%$ of world's electricity, with a quarter of it being contributed by wind power according to the International Energy Agency (IEA) [1]. Approximately $318 \mathrm{GW}$ wind power sources were installed over the world by the end of 2013 and China has installed $81 \mathrm{GW}$ of these wind power sources, which is approximately $25 \%$ of the total worldwide installations. Furthermore, it is expected that this would increase to $200 \mathrm{GW}$ by 2020 [2]. A majority of the wind power bases and thermal power bases are located in the northern and western areas of Mainland China and a huge percentage of these two kinds of bases are located more than a few thousand kilometers away from the load centers. Wind power is characterized by stochastic fluctuation in nature, which requires available peaking power resources to stabilize the system. The thermal power plants which are built around the large-scale wind power bases can be an effective means for stabilizing the fluctuation of wind power output. Wind-thermal-bundled power system by DC transmission is regarded as a preferable means for power generation in the northern and western areas of Mainland China [3]. Conventional renewable source of energy transmission and the bundled system meets the basic requirements for a large also ensures smooth DC power delivery and improved transmission. However, challenges still exist related to DC transmission technology and stability of the power grid when considering the bundled system.

Since, thermal power plants, wind farms and load centers may have large distance between them, high voltage direct current (HVDC) technology, including line-commutated converter HVDC (LCC-HVDC), voltage source convertorHVDC (VSC-HVDC) and hybrid HVDC are preferred [4].

\footnotetext{
* Address correspondence to this author at the Department of College of Electrical Engineering, Xinjiang University, Urumqi, XinJiang, China; Tel: +86-18399698695; E-mail: wjha29@sina.com.
} 
LCC-HVDC and VSC-HVDC systems are two typical HVDC systems, which are used for transmission from large wind farms to grid. Conventional LCC-HVDC systems are among the most widely used HVDC technologies around world. These systems have advantageous features such as the low power loss, and highest power capability. The cost for conventional LCC-HVDC systems among the HVDC systems is significantly lower. However, the LCC system has drawbacks such as high commutation failure and increases harmonics [5]. Recently, VSC using pulse width modulation (PWM) is being increasingly used as an alternative technology for HVDC transmission due to its independent control of both active and reactive powers and the possibility to feed a weak AC system. But VSC-HVDC systems are expensive and have high loss but smaller ratings compared to conventional LCC converters [6].

In order to combine advantages of both LCC and VSC, a hybrid HVDC system is proposed in this paper, which was first introduced in 1994 [7]. Since different converters are used, hybrid HVDC systems can be more advantageous than conventional HVDC systems. For inverter side of a HVDC system, capability for flexible reactive control is necessary to integrate grids. The VSC can be placed at the receiving end of an existing grid, which would offer more flexible control over conventional LCC [8]. For rectifier side of a HVDC system, LCC is cheap for long distance transmission and is widely used by its technical maturity [9]. Hybrid HVDC systems are aimed at compensating the above mentioned disadvantages for both two types of converters, allowing for better technical and economical outcomes.

Author in [10] proposed a feasible structure for a hybrid HVDC system, which has a VSC at the receiving end and a LCC at the sending side. A hybrid HVDC system can be a solution for integrating offshore wind farms which feed into the main land. Author in [11] used a two-terminal hybrid HVDC system, which consists of a pulse width modulated current source converter (PWM-CSC) and a LCC to transfer energy from offshore wind farms to onshore grids. Dynamic performance of a VSC based series hybrid HVDC has been studied for supplying a weak AC system [12]. Controller designing for a hybrid HVDC system with a LCC and VSC has been proposed [13]. Author in [14] discussed the mathematical mode and operational mechanism of a hybrid HVDC link. In addition, a discussion on a MTDC system for multi-infeed to AC networks was presented in $[15,16]$. Hybrid MTDC systems with a hybrid infeed of VSC and LCC to a passive load was discussed in [17]. A multi-terminal HVDC with all VSC converters connected to offshore wind farms with disturbance had also been proposed as an example to reflect conditions for practical applications [18]. So far, limited numbers of multi-terminal HVDC projects have been implemented around the world, which include the five-terminal VSC-HVDC system established in Zhoushan, China on June 27, 2014 and the southwest link between Sweden and Norway will be built in 2016.

Due to the stochastic fluctuation of wind speed, wind farms are regarded as a weak AC system [19]. This has considerable impact on the stability of the connected power grids. In this paper, thermal power plants were used to compensate for the fluctuations in wind power. A hybrid three-terminal HVDC system designed is proposed, which includes two LCC converters at the sending terminals and one VSC converter at AC grid terminal. Transient stability of the power system with bundled transmission of wind and thermal power has been studied taking practical requirements into account specific to the Northwest Grid in China, Control strategies and principles of the proposed system have also been presented. Successful operations during wind speed variations and faults on the grid side were verified with simulations using DIgSILENT.

\section{SYSTEM CONFIGURATION}

\subsection{Hybrid MTDC Configuration}

A simple way to establish a MTDC system can be based on the configuration of an existing AC transmission system [20]. This paper addresses design issues pertaining to local thermal power plants with interconnecting wind generation zones based on an existing AC grid. The basic configuration of a hybrid three-terminal HVDC system is shown in Fig. (1). This hybrid MTDC system comprises of two LCC rectifiers at the sending end, which are connected to the wind farms and thermal power plants. One VSC inverter is connected at the receiving end. It assumed here that all converters employ a 12-pulse structure. The LCC consists of filters and an equivalent resistor, a commuting transformer, antiparallel diodes and thyristors. The VSC converter comprises of an insulated-gate bipolar transistor (IGBT) based bridges, a shunt AC-filter, converter reactor and capacitor [21]. 


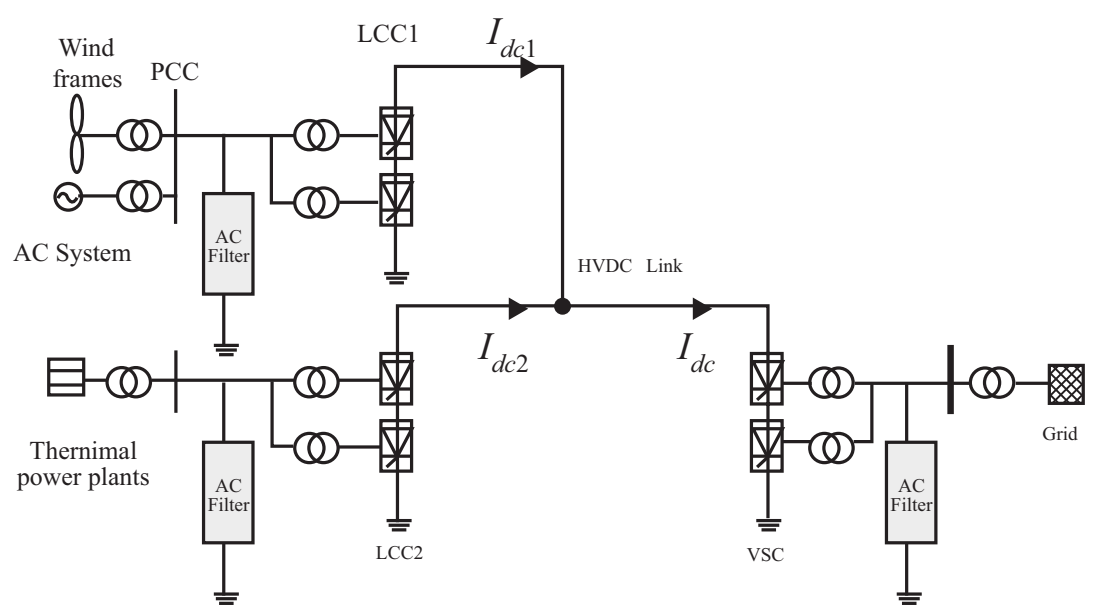

Fig. (1). Configuration of hybrid MTDC for proposed system.

\subsection{Wind Disturbance Models}

One problem associate with most of the studies discussed in the preceding sections is that they treat wind speed as constant or as a gust, ramp and stochastic form while carrying out simulation of the wind power system. Modeling wind speed as in such a manner does not completely reflect the transient characteristics of wind farms. Choice of the correct model for wind speed is highly significant in wind power research, as it can reflect actual wind speed changes, while also providing accurate parameters for simulation and study of the wind power system [22]. Typical wind speed forms are discussed in this paper in order to get equivalent wind speed with embedded noise.

There are three common forms of wind disturbance and they can be classified as gust, ramp and stochastic forms. Gust wind is used to indicate a sudden change in wind speed and the mathematical model is given as,

$$
V_{G}=\left\{\begin{array}{lc}
0 & t<T_{1} \\
0.5 V_{G}\left\{1-\cos \left(2 \pi\left(t-T_{1}\right) /\left(T_{2}-T_{1}\right)\right)\right\} & T_{1} \leq t \leq T_{2} \\
0 & t>T_{2}
\end{array}\right.
$$

Where, $V_{G}$ is the amplitude of the gust wind. $T_{1}$ and $T_{2}$ are the start and end times of gust wind. Ramp wind is used to indicate a gradual change in wind speed. The model of ramp wind is given as,

$$
V_{R}=\left\{\begin{array}{lc}
0 & t<T_{S} \\
V_{R}\left(t-T_{S}\right) / T_{r} & T_{S} \leq t<T_{S}+T_{r} \\
V_{R} & T_{S}+T_{r} \leq t<T_{e}-T_{d} \\
V_{R}\left(T_{e}-t\right) / T_{d} & T_{e}-T_{d} \leq t<T_{e} \\
0 & t \geq T_{e}
\end{array}\right.
$$

Where, $T_{r}$ is the time taken by wind to change speed from zero to amplitude. $T_{d}$ is the time taken by wind to change speed from amplitude to zero. $T_{s}$ and $T_{\bar{a}}$ are the start and end times of ramp wind. $V_{R}$ is amplitude.

Stochastic wind is used to indicate uncertainty and random characteristics of wind speed. The model of the stochastic wind is given as,

$$
\begin{gathered}
S_{V}\left(\varpi_{i}\right)=2 K_{N} F^{2}\left|\varpi_{i}\right| /\left\{\pi^{2}\left(1+\left(F \varpi_{i} /(\mu \pi)\right)^{2}\right)^{4 / 3}\right\} \\
V_{S}=2 \sum_{i=1}^{N}\left(\sqrt{S_{V}\left(\varpi_{i}\right)} \Delta \varpi \cos \left(\varpi_{i} t+\varphi_{i}\right)\right)
\end{gathered}
$$




$$
\varpi_{i}=(i-0.5) \Delta \varpi
$$

Where, $K_{N}$ is roughness coefficient of the earth surface. $F$ is a disturbance scale for the stochastic wind, $\mu$ is average wind speed, $N$ is the sample used for wind speed, $i$ is tab number, $\Delta \varpi$ is the interval of noise sampling frequency and $\phi_{i}$ is a random variable which is uniformly distributed between 0 and $2 p . S_{V}$ means the amplitude of $\phi_{i}$ and $V_{G}$ is the stochastic wind.

\section{CONTROL OF THIS SYSTEM}

\subsection{Overall Control of this System}

For the MTDC system, the control strategy combines both the LCC-HVDC and VSC-HVDC systems as shown in Fig. (2). Different control schemes were utilized on both sides of MTDC system. A master controller was designed to generate DC voltage using the VSC inverter. This is done so that the DC voltage is maintained at a constant value when different operations are carried out in a hybrid system. At the sending side, the LCC1 is controlled to track maximum power, whereas, LCC2 is used in compensate wind power mode.

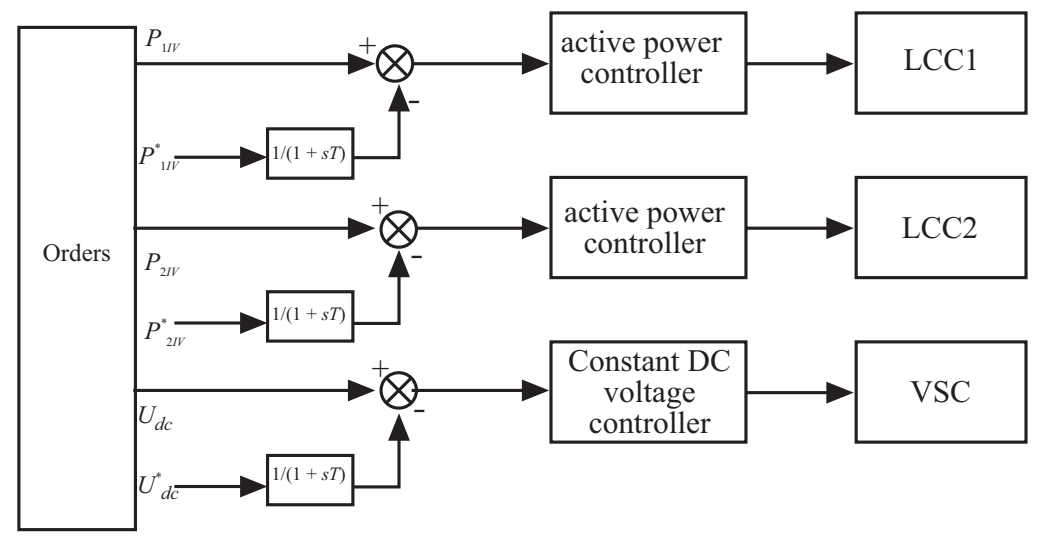

Fig. (2). Overall control structure of MTDC system.

\subsection{LCC Controllers at the Sending End}

Controller for both LCC1 and LCC2 rectifier stations with the implemented double-loop PI controllers are shown in Figs. (3 and 4). The outer loop power controller utilizes power tracking logic and the inner loop current controller was designed for a quick response acting as a protection for the thyristor valves. $P_{1 W}$ is the wind power while $P^{*}{ }_{1 W}$ the reference. $P_{2 W}$ is the thermal power while $P_{2 W}^{*}$ the reference. $I_{d c 1}$ is DC current of LCC1 $I_{d c 1}^{*}$ with as the reference. $I_{d c 2}$ is DC current of LCC2 with $I_{d c 2}^{*}$ as the reference. Both parameters are inputs to the LCC1 controller and LCC2 controller, respectively. These parameters were used to obtain the corresponding firing angle $\alpha$.

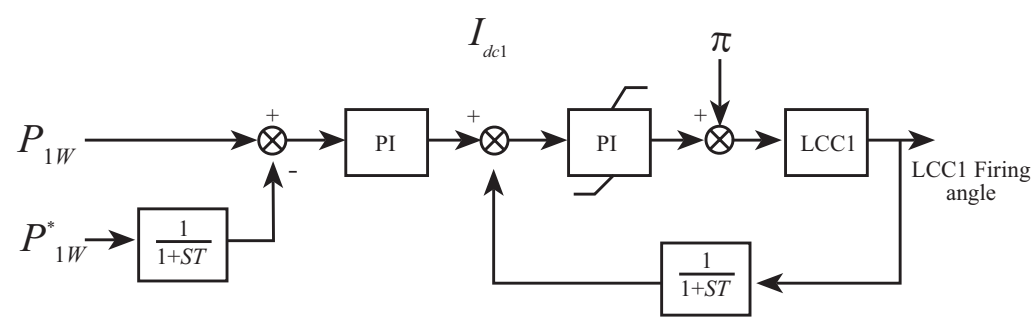

Fig. (3). Double-loop controller for LCC1. 


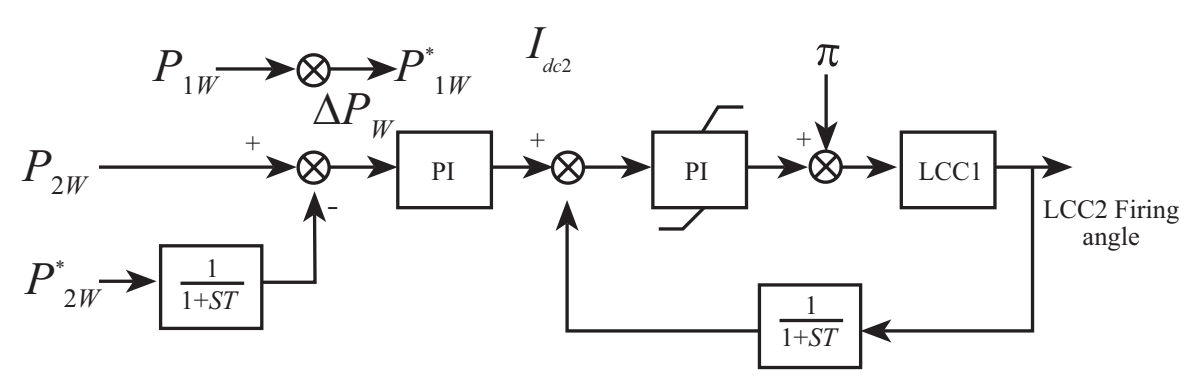

Fig. (4). Controller for LCC2.

Fig. (4) shows the controller for the LCC2 rectifier station that connects to the thermal power plants. A feed-forward controller is added by comparing with the wind power $P_{1 W}$ and its reference $P^{*}{ }_{1 W}$ to generate an accessory value $\Delta P_{W}$ in LCC2. So that the thermal power can compensate the fluctuation of wind power and make a stability output in grid power.

\subsection{VSC Controller at the Receiving End}

To balance active power of the DC network transmission, one converter station must apply DC voltage control strategy for the hybrid MTDC link. Fig. (5) shows the control strategies for the receiving end converter station VSC, which utilizes DC voltage and reactive power control.

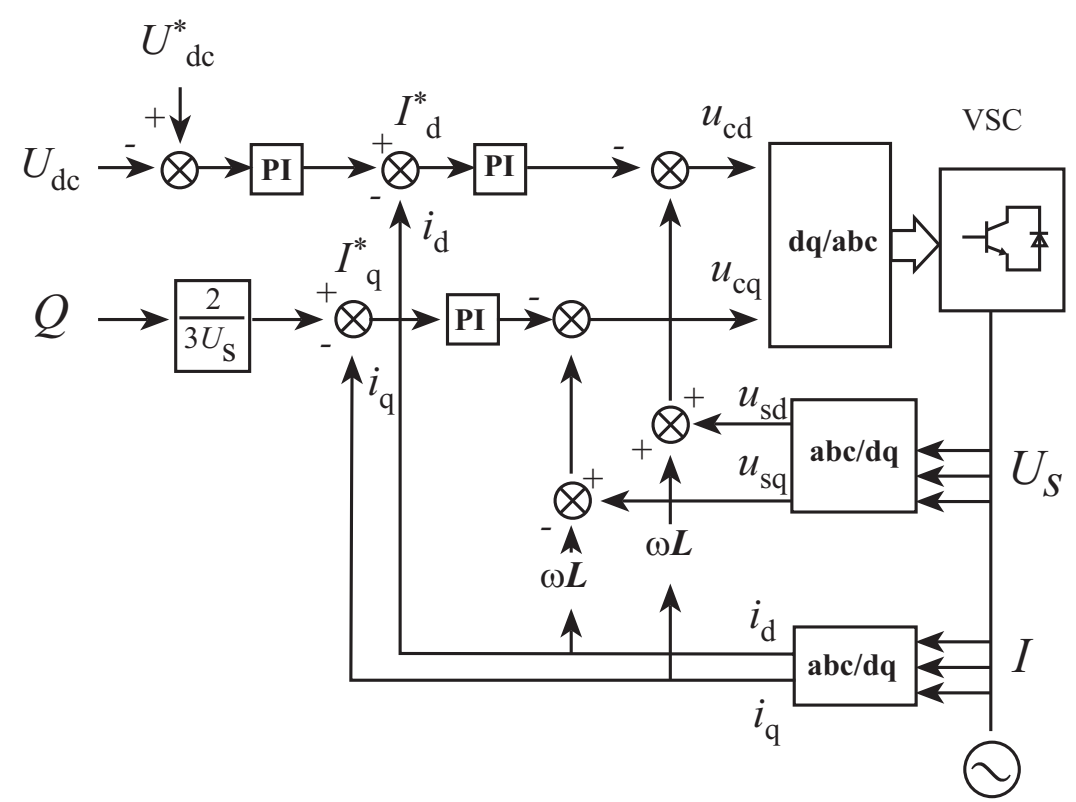

Grid

Fig. (5). Controller for VSC.

In Fig. (5), $U_{d c}$ represents the value for the DC voltage while $U_{d c}^{*}$ is the reference value. And $Q$ is the value for the reactive power. $I_{d}^{*}$ and $I_{q}^{*}$ are the reference values corresponding to the d and q-axis current. These control strategies for VSC can control DC voltage and reactive power independently.

\section{SIMULATION AND DISCUSSION}

The proposed system was simulated using DIgSILENT. A large-scale wind farms typically consist of a ten to a few hundred wind turbines. However, for this case, it is represented as one generator which can be a simplified configuration of a hybrid MTDC system. Main parameters of the system have reference to CIGRE benchmark HVDC model [23]. 


\subsection{Response to Wind Speed Variation on the Sending End}

Fig. (6) shows the noise wind speed described by eq. (1) to (5). The nominal wind speed is $11 \mathrm{~m} / \mathrm{s}$, then at $\mathrm{t}=0 \mathrm{~s}$ a wind speed gust occurs which increases amplitude $5 \mathrm{~m} / \mathrm{s}$ with $2 \mathrm{~s}$ of duration. The ramp wind increases the nominal wind speed at a rate of $3 \mathrm{~m} / \mathrm{s}$ at $\mathrm{t}=2 \mathrm{~s}$ in $20 \mathrm{~s}$. The wind is noisy throughout the simulation. Fig. (8) shows the performance of the bundled system for a noisy wind speed of $11 \mathrm{~m} / \mathrm{s}$. Simulation results show that the mathematical model accurately reflects mutation of a gradual nature and randomness in wind speed.

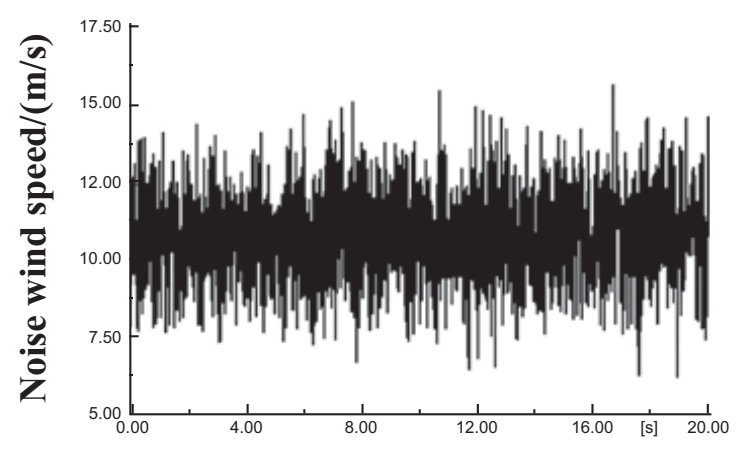

Fig. (6). Wind speed.

Fig. (7a and b) show the output active power from wind farm and thermal power plant. The stochastic and uncertainty of the wind power can be canceled by thermal power. Wind generator speed is about $1.2 \mathrm{pu}$ and thermal generator speed is $1 \mathrm{pu}$, as can be seen in Fig. (7c). Fig. (7d) shows DC voltage at the LCC converters and VSC converter. It can be seen from the figure that all voltages are at their nominal values.

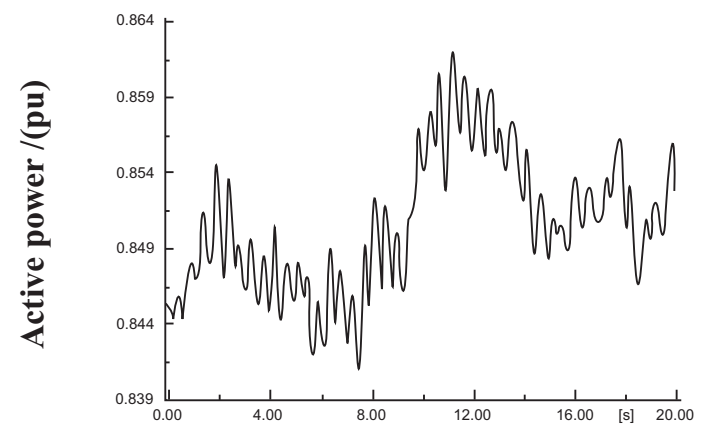

(a)

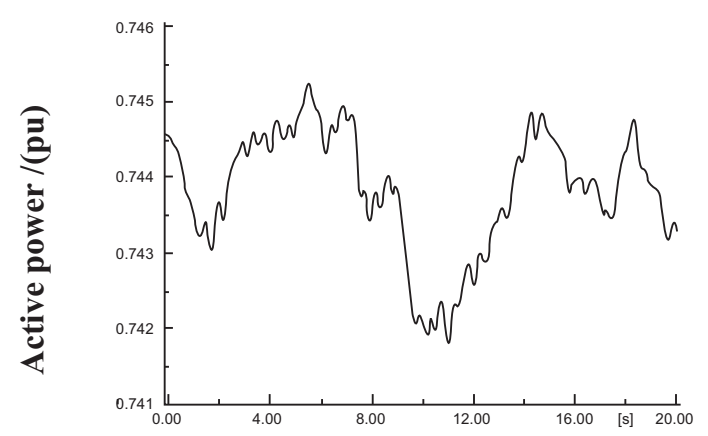

(b)

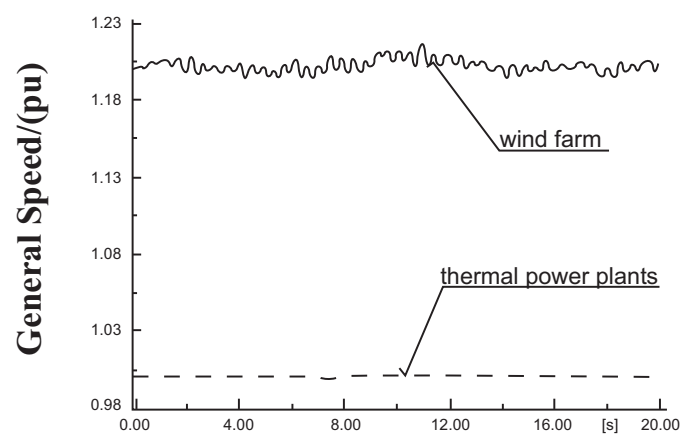

(c)

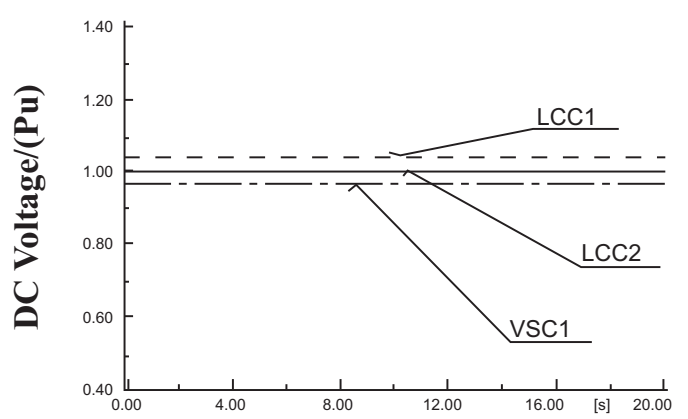

(d)

Fig. (7). Simulation results with noise wind speed (a) Wind power. (b) Thermal power. (c) Generator speed. (d) DC voltage of each converter. 


\subsection{Three-phased Short Current Fault of VSC Inverter on the Receiving End}

In this study, it is assumed that a three-phase short circuit fault occurs on the AC side of VSC inverter at $2 \mathrm{~s}$ and is cleared after 0.1s. Simulation results are shown in Fig. (8).

The AC voltage at the fault terminal drops down to zero temporarily, which causes a decrease in the DC voltage for other converters and is shown in Fig. (8a and b). When fault occurs and AC voltage of VSC drops to $0.5 \mathrm{pu}$, an off signal will be produced to prevent damage to the IGBT by PWM to maintain power balance and system stability. Although wind active power drops to nearly zero, the output active power of the thermal power plants adds 4.3 pu to compensate the wind power. Fig. (8e) shows rotor current of DFIG, it can be seen that the fault has a small impact on the DFIG.

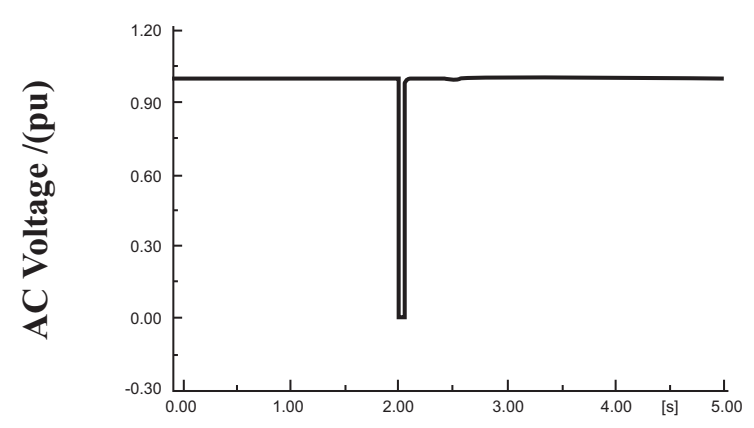

(a)

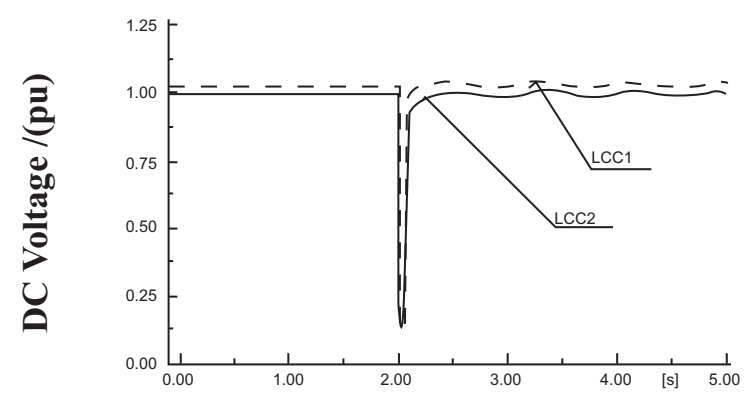

(b)

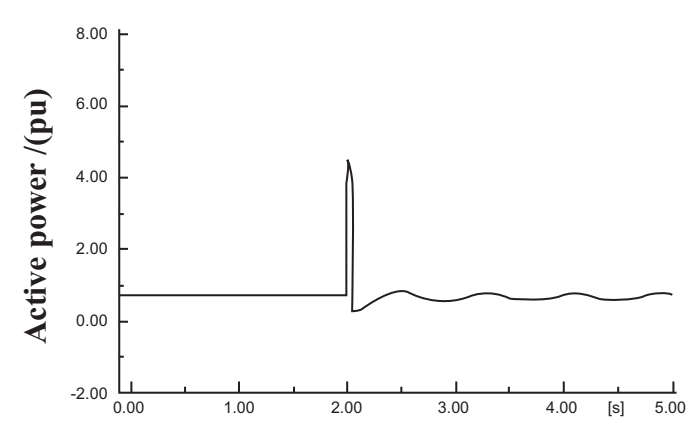

(c)

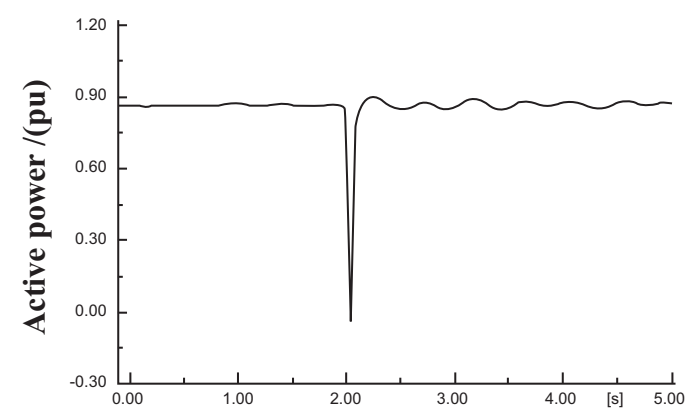

(d)

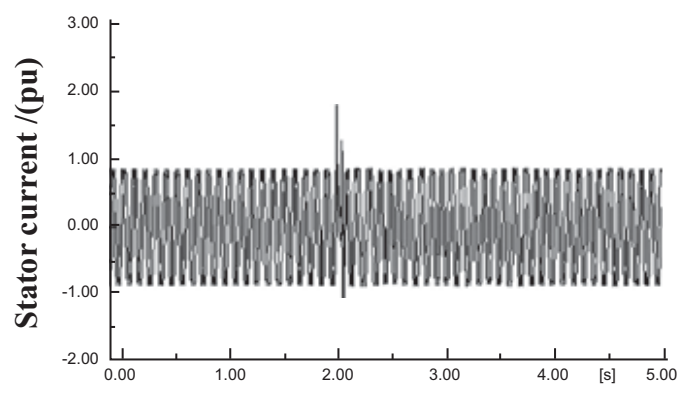

(e)

Fig. (8). System responses to the fault at the VSC inverter. (a) AC voltage of VSC. (b) DC voltage of each converter. (c) Thermal power. (d) Wind power. (e) DFIG stator current.

\subsection{Load Change at VSC Inverter on the Receiving End}

Since, the hybrid MTDC system has advantages such as low convention loss, control flexibility and terminal voltage support. This section studies the dynamic performances of the proposed hybrid based scheme and shows it to be superior to a purely conventional LCC based scheme. And this section consists two cases of a three terminals HVDC system. 
Case 1. The two converters at the sending end are LCCs while the recceing end is a VSC, as in Fig. (1).

Case 2. All converters are LCCs, as in Fig. (9).

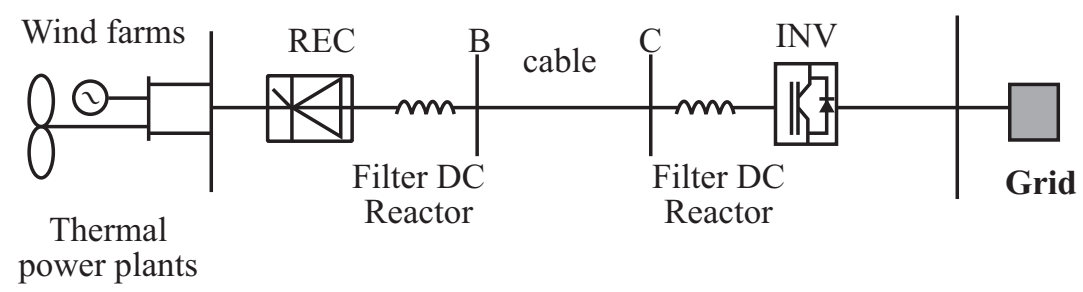

Fig. (9). Configuration of conventional LCC MTDC for proposed system.

To investigate both systems' responses to the dynamic disturbance, a $30 \%$ decrease in load at the inverter side is applied at $2 \mathrm{~s}$ for a duration of $0.2 \mathrm{~s}$. System performances for this section are presented in Fig. (10).

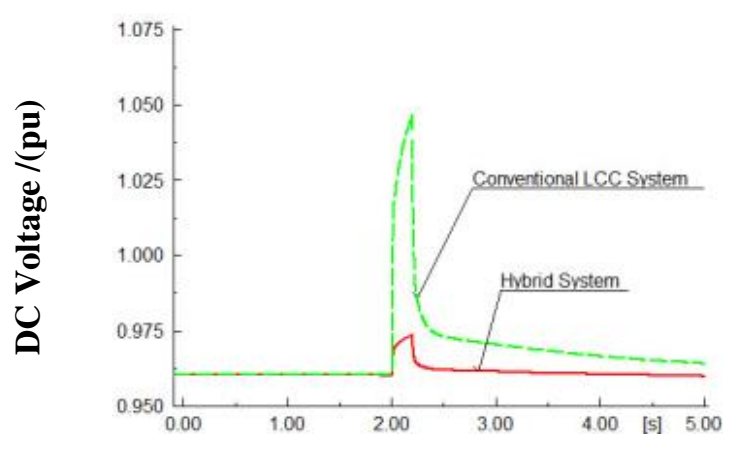

(a)

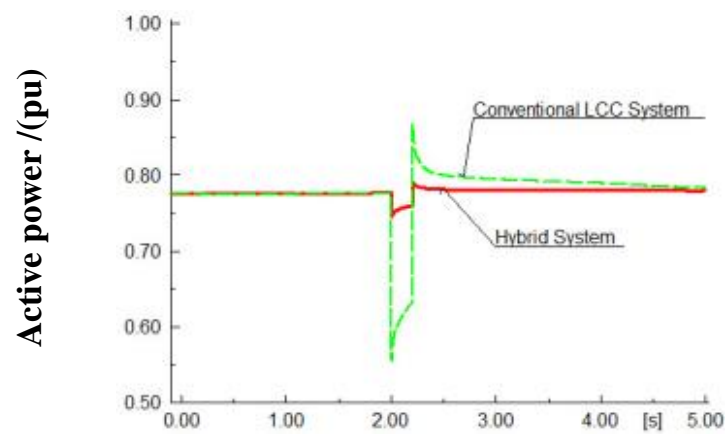

(b)

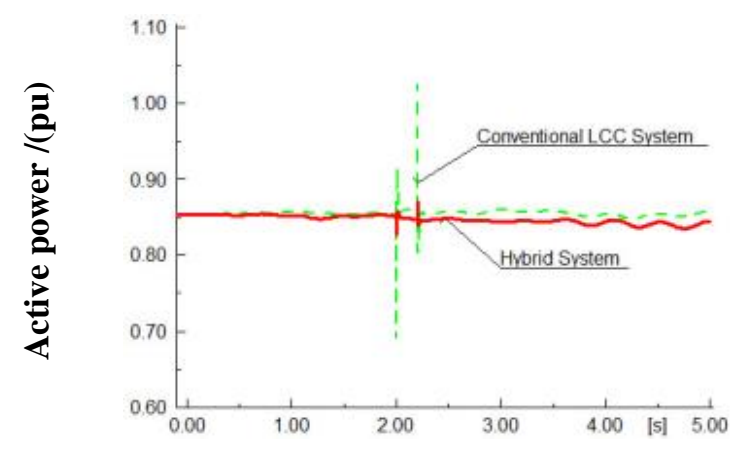

(c)

Fig. (10). System responses to load change at the VSC inverter. (a) DC voltage of receiving end of two cases. (b) The change of thermal power of two cases. (c) The change of wind power of two cases.

Load decrease causes a decrease in the active power requirements, which increases DC voltage at the receiving converter and is shown in Fig. (10a). The VSC on the receiving end has to decrease the power absorbed from the DC network quickly to keep the DC voltage. Therefore, terminal voltage of the hybrid system remains almost unaffected. However, the conventional LCC system is affected which increases AC voltage to about 0.1pu. The thermal active power of conventional LCC system decreases from $0.85 \mathrm{pu}$ to $0.55 \mathrm{pu}$ and it uses $2.8 \mathrm{~s}$ to recover to its original value. However, the thermal active power of the hybrid system decreases from $0.85 \mathrm{pu}$ to only $0.81 \mathrm{pu}$ and system can recover fast after the load is back to normal, seen in Fig. (10b). The active power performances of wind farms are the same to the thermal power plants, seen in Fig. (10c). This demonstrates that the hybrid MTDC system is more capable of dealing with load change than a conventional LCC system. 


\section{CONCLUSION}

This paper proposes a hybrid MTDC system, which connects remote load centers into existing resources (windthermal-bundled power system). Furthermore, control strategies for design of each converter are proposed. Based on the different simulation results, following conclusions can be made:

a. Fluctuation in wind power embedded with noise can be compensated by thermal power and the system can tolerate such variations in wind speed.

b. A three-phase short current fault of VSC on receiving end or load change does not severely impact the sending end and there is no communication failure. The hybrid MTDC system was able to deal with load change in a passive network.

c. Peak load regulation for thermal power cannot fully meet wind power, due to this some additional research, which takes in consideration the addition of energy storage systems will be incorporated into future work.

\section{CONFLICT OF INTEREST}

The authors confirm that this article content has no conflict of interest.

\section{ACKNOWLEDGEMENTS}

This work was supported by The Opening Foundation of National Laboratory of XinJiang Province (2016D03021).

\section{REFERENCES}

[1] GWEC, "Global Wind", Report, Global Wind Energy Council: Brussels, 2014.

[2] L. Jiang, Y. Chi, and H. Qin, "Wind energy in China", IEEE Power \& Energy Magazine, vol. 6, pp. 36-46, 2011. [http://dx.doi.org/10.1109/MPE.2011.942350]

[3] D. Chen, S. Ma, and Y. Song, "Research on transient stability under HVDC block fault in wind-thermal-bundled power base transmitted by AC/DC system", In: 2014 International Conference on Power System Technology (POWERCON 2014), IEEE Publisher, USA, 2014, pp. 2884-2890.

[http://dx.doi.org/10.1109/POWERCON.2014.6993894]

[4] R.L. Sellick, and M. Akerberg, "Comparison of HVDC Light (VSC) and HVDC Classic (LCC) Site Aspects for a 500MW 400kV HVDC Transmission Scheme", In: 10 IET International Conference on AC and DC Power Transmission, IEEE Publisher, USA, 2012 , pp. $23-29$.

[5] M.D. Miguel, S.M. David, and S. Arnaltes, "Optimal reactive power allocation in an offshore wind farms with LCC-HVdc link connection", Renewable Energy, vol. 40, pp. 157-166, 2011.

[6] Y. Jie, Y. Yang, Z. He, and H. Wang, "System design of MMC VSC-HVDC demonstration project for wind farm connection", In: $10^{\text {th }}$ IET International Conference on AC and DC Power Transmission, IEEE Publisher, Bermingham, UK, 2012, pp. 14-18.

[7] Z. Zhao, and M.R. Iravani, "Application of GTO voltage source inverter in a hybrid HVDC link", IEEE Transaction on Power Electronics., vol. 9 , pp. 369-377, 1994. [http://dx.doi.org/10.1109/61.277708]

[8] B. Qahraman, and A. Gole, "A VSC based series hybrid converter for HVDC transmission", In: Electrical and Computer Engineering Conference, IEEE Publisher, Vancouver, China, 2005, pp. 458-461. [http://dx.doi.org/10.1109/CCECE.2005.1556970]

[9] Mai H. Nguyen, Mehdi Eghbal, and Tapan K. Saha, "Hybrid multi-terminal LCC HVDC with a VSC Converter", In: A Case Study of Simplified South East Australian system PES General Meeting, IEEE Publisher, USA, 2012, pp. 1-8.

[10] Li Wang, "Stability Analysis of Different Offshore Wind Farms Feeding into a Large Power Grid through a Hybrid HVDC Link", In: Industrial Electronics (ISIE) 2013 IEEE International Symposium, IEEE Publisher, Taiwan, 2013, pp. 1-6.

[11] E. Raymundo, T. Olguin, and A. Garces, "Integration of offshore wind farm using a hybrid HVDC transmission composed by the PWM current-source converter and line-commutated converter", IEEE Transaction on Energy Conversion., vol. 28, pp. 125-134, 2013. [http://dx.doi.org/10.1109/TEC.2012.2230535]

[12] R. Billinton, M. Fotuhi-Firuzabad, and S.O. Faried, "Reliability evaluation of hybrid multi-terminal HVDC sub-transmission systems", In: IET Proceedings Generation Transmission and Distribution, vol. 149. 2002, pp. 571-577.

[13] R.E. Torres-Olguin, M. Molinas, and T.M. Undeland, A Model-based Ccontroller in Rotating Reference Frame for Hybrid HVDC., IEEE Energy Conversion Congress and Exposition, IEEE Publisher, USA, 2010, pp. 1578-1584. [http://dx.doi.org/10.1109/ECCE.2010.5618087]

[14] L. Guangkai, L. Gengyin, and L. Haifeng, "Operational mechanism and characteristic analysis of novel hybrid HVDC system", In: 2006 International Conference on Power System Technology, IEEE Publisher, China, 2006, pp. 1-6. 
[15] R. Chunyi Guo, and C. Zhao, "Supply of an entirely passive network through a double-infeed HVDC System", IEEE Transaction on Power Electronics., vol. 24, pp. 2835-2841, 2010. [http://dx.doi.org/10.1109/TPEL.2010.2050214]

[16] Y. Liu, and Z. Chen, "Power Control Method on VSC-HVDC in a Hybrid Multi-infeed HVDC system", In: IEEE Power and Energy Society General Meeting, IEEE Publisher, Canada, 2012, pp. 1-8.

[17] G Shilpa, and Premila Manohar, "Hybrid HVDC System for Multi-infeed Applications", In: Emerging Trends in Communication, Control, Signal Processing \& Computing Applications (C2SPCA), IEEE Publisher, Banglore, India, 2013, pp. 1-5.

[18] W. Lu, and B.T. Ooi, "Optimal acquisition and aggregation of offshore wind power by multi-terminal voltage-source HVDC", IEEE Transactions On Power Deliver, vol. 18, pp. 201-206, 2003. [http://dx.doi.org/10.1109/TPWRD.2002.803826]

[19] H. Zhou, G. Yang, and J. Wang, "Control of a hybrid high-voltage DC connection for large doubly fed induction generator-based wind farms", IET Renewable Power Generation, vol. 5, pp. 36-47, 2010. [http://dx.doi.org/10.1049/iet-rpg.2009.0171]

[20] H.B. Jiang, and E. Ake, "Multi-terminal HVDC systems in urban areas of large cities", IEEE Transactions on Power Delivery, vol. 13, pp. $1278-1284,1998$.

[http://dx.doi.org/10.1109/61.714496]

[21] M.O. Faruque, Y.Y. Zhang, and V. Dinavahi, "Detailed modeling of CIGRE HVDC benchmark system using PSCAD/EMTDC and PSB/SIMULINK", IEEE Transactions On Power Delivery, vol. 21, pp. 378-387, 2006. [http://dx.doi.org/10.1109/TPWRD.2005.852376]

[22] S. Hao, Y. Zhang, and X. Li, "Equivalent wind speed model in wind farm dynamic analysis", In: Electric Utility Deregulation and Restructuring and Power Technologies, DRPT, IEEE Publisher, China, 2011, pp. 1751-1755.

[23] M. Szechtman, T. Wess, and C.V. Thio, "A benchmark model for HVDC system studies", In: International Conference on AC and DC Power Transmission, IEEE Publisher, UK, 1991, pp. 374-378.

(C) Jiahui et al.; Licensee Bentham Open

This is an open access article licensed under the terms of the Creative Commons Attribution-Non-Commercial 4.0 International Public License (CC BY-NC 4.0) (https://creativecommons.org/licenses/by-nc/4.0/legalcode), which permits unrestricted, non-commercial use, distribution and reproduction in any medium, provided the work is properly cited. 